\title{
Student of Water Tanks Characteristics for Residential and Commerical Buildings in Oman
}

\author{
Ahmed Rashid Said Al Ismaili \\ Dr. Adeel H. Suhail \\ MIDDLE EAST COLLEGE \\ Middle East College
}

\begin{abstract}
Water tank is an important element in water distribution system. The project is studied the characteristics of water tanks and the main objective of it to identify the selection criteria for the water tank. Furthermore, Selection of water tank is a challenge for many individuals and companies. The study is gathers information from many sources such as literature reviews, companies, questionnaire and experts in order to reach to the main important characteristic of water tanks. The selection of water tank depends heavily on the applications. As a result, it found that the best type of storage tanks for sweet water used for human consumption are two types, one of which is polyvinyl chloride to store a quantity of less than five cubic meters and the other is stainless steel tank to store more than five cubic meters. The study found that the best reservoir for irrigation and sewage uses is the carbon steel tank. On the other hand, the study found that the stainless-steel tank is best suited for storage of seawater, which requires a material that can withstand corrosion.
\end{abstract}

\section{Introduction}

Water tanks are usually used to meet storage requirements, demand and pressure desired for the system used. In addition, these storage services drained and filled based on the respond to system demand capacity. Water tanks are usually located in a planned location in order to retain constant demand or pressure in the system (Olson and DeBoer 2007).

A large proportion of people saves, transfers and stores the water for many purposes such as drinking, food preparation and home cleaning. Study specifies that optimizing water source for people is not always safe water at the using point and quality often declines later (Graham and VanDerslice 2007).

Storage tanks is classified into different types based on the material used in manufacturing them. Moreover, the primary materials used to construct tanks are either steel or concrete (Everhart 2010). Besides, modern water storage tanks can be made from another different materials such as Polyvinyl chloride, polyethylene and fiber-glass as shown in figure 1-1 and figure 1-2. However, water tank can be manufactured with different forms such as cubical shape and cylindrical tank (Erosion Pollution 2011).

Water tanks is a dangerous element of water supply systems. However, they can pose a major challenge for water utilities as they regularly create a harmful influence on water quality. Water quality issues can grow because of low turnover or insufficient mixing subsequent later in shortcircuiting (Duer 2006).

Kotler et al. (2013) has defined the target audience as the anticipated audience of a journal, advertisement, or other communication. In marketing, it is a certain set of customers inside the determined target market, recognized as the aims and inheritors for a specific advertisement or communication media. In this research the targeted audiences were individuals and businesses. The targeted Individuals in the project have selected to improve storage tank selection. Moreover, 
house and building owners is the most common people that use water tank. Also, the project helps commercial like companies and industries to develop their selection of water storage tank and to distinguish among water storage tank types. The classification of the targeted audiences in this project are shown in figure 1-5. Besides, the project helps water storage tank producers to choose the correct tank material based on the application and using location.

Selection of water tank is a difficult challenge which people found it an obstacle during purchasing water tank that could lead to wrong selection and face many problems in future. The main goal of this project is to identify the selection criteria of water tanks for different applications and environments, which could lead to identify the influences of tanks on environment, study the effective cost of water tanks and the influences of tanks on water and human being health.

\section{Research Methodology}

The project is made a research on characteristics of water tank for residential and commercial applications in Oman. This research helps the targeted audiences for optimizing the water tank selection. There are sequential processes that the project has followed them in order to implement the study. The project is collected data using four sources. First, it has made reviews on the earlier literatures to obtain information and learn from earlier experiences and outcomes. Second, it is carried out a survey about the most common tank existing in Oman and the important characteristics required for water tank selection. Third, it is used some required data from companies that available in Oman. Fourth, it is implemented experts' interview to reach to the most important characteristics needed for water tank selection.

This information is analyzed using several methods as follows: Using tables, graphs, diagrams and material substitution method. Material substitution method is one of the most popular methods used in selecting the most suitable materials for the product. In this study, this method is used to obtain the best characteristics of the water tank for several selected applications.

However, the study is focused on the following scope. The thermal insulation efficiency of the water tanks by analyzing thermal conductivity of each type of water tank. Then, it is studied the most characteristics that has influences on selection of water tank like lifetime of the product, stress resistance, chemical reaction and environmental effect. It also studies the influences of tank on water tank and then on the human being. Finally, it evaluates the cost of water tanks based on the application.

Figure 1 shows the methodology processes and the procedures followed to implement the research. 


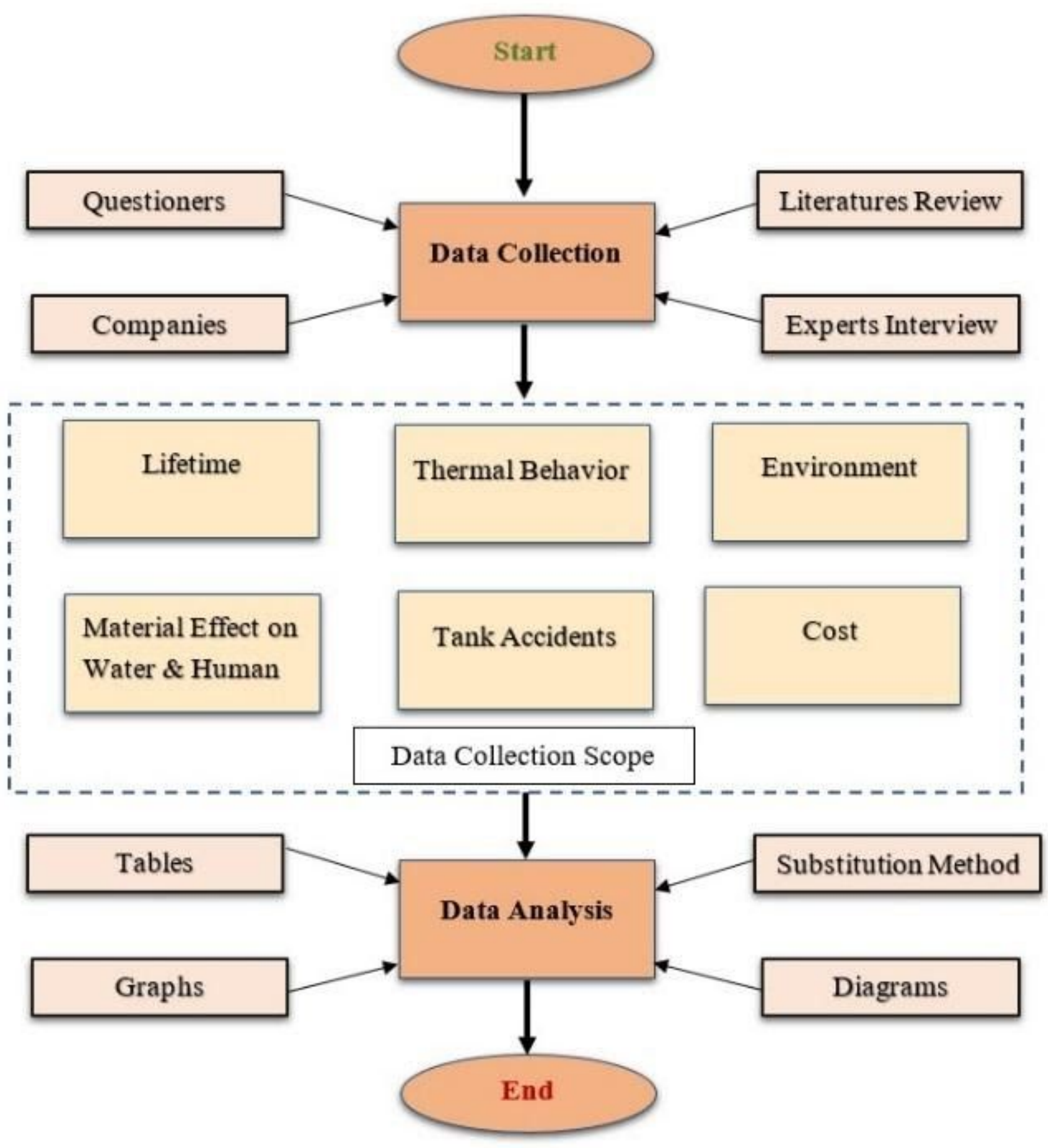

Figure 1. Research methodology processes.

\section{Data Collection Procedure}

There are many sources that have been used to aggregate the information as shown in Figure 2.

Figure 2. Data collection sources. 


\section{Companies}

Many data are collected from different companies (Manufacturers and Suppliers). Table 1 shows the manufacturers and suppliers of water tanks in Oman and explains the type of materials manufactured and the method of manufacture used.

Figure 3. Common Manufacturers and Suppliers of Water Tanks in Oman

\section{Expert interviews}

Several experts were interviewed to study the characteristics of water tanks in Oman. Mr. Desai is a senior engineer in the field of mechanical engineering at Alturki Company where he was discussed the characteristics of water tanks in Oman. Desai spoke of the importance of the water tanks and he stated that the selection must be "in accordance with the requirements" in which the requirement may change based on the application. For example, for domestic water tank the material of tank must be very resistant to corrosion and that the choice of water tanks mostly depends on this factor. Domestic water tank may be used for drinking and other human applications so the material must be safe and the materials that do not bear the corrosion should be excluded from the beginning so that the choice is not affected.

"Water tank is one of the most important parts of water supply systems" said Mr. Gobi from Galfar Engineering Company. He also stated that its importance is that it conserves water for a certain period of time to ensure the availability of water for the building or any other use so as not to be affected by any sudden interruption of the source. Moreover, "the selection of water tanks is an important step because the selection of any bad material may cause water pollution and thus also affect the health of humans or living organisms if the water is used for drinking or irrigation" said Mr. Gobi. However, he also stated that the most important characteristics affecting the selection of the tank is the resistance of the tank material to corrosion and the price of the tank and the strength of the tank, especially if the volume of the tank is large.

Mr. Hilal from Royal Court Affaires said that the most common materials from which the tanks are made include metal, polymers, stainless steel, and fiberglass. The use of any of these materials has its advantages and disadvantages. From an economic point of view, the most common material is the plastic. Plastic Tanks have a relatively low cost and non-corrosive. They also are resistant to many chemicals.

\section{Questionnaire}

A survey has been conducted to determine the user assessment of water tanks in Oman. A good number of users participated in this questionnaire. In the following figures, the results of this questionnaire are presented in the form of graphs that illustrate the opinions of water tank users (Refer Appendix 1 for Questionnaire Form).

\section{Results}

Figure 3 shows type of building of persons participating in the questionnaire, which shows that $72.5 \%$ of the participants use water tank for domestic applications while $37.5 \%$ are commercial applications. 
Figure 4. Users building type.

Figure 4 shows type of participant's water tank, which shows that $72.5 \%$ of the participants use plastic water tank while $7.5 \%$ of them use metal water tank and $30 \%$ of them use fiberglass water tank (FRP).

Figure 5. Water tank material.

Most of the participants (80\%) in this questionnaire put the water tanks in the roof of the building, $12.5 \%$ of them put them on the ground, and the rest put them in a plant room or on a bridge as shown in figure 5.

Figure 6. Water tank location.

Figure 6 shows the users opinion about the price effect on water tank selection. However, figure 7 shows the users opinion about the material behavior on water tank selection.

Figure 7. Price Effect on Water Tank Selection.

Figure 8. The effect of material behavior Effect

Figure 9. The effect of shape and color

Also the users were asked different questions such as:

- Whether there is a significant increase in water temperature within the water tank during summer.

- If they provide shade for the water tank.

- If they use thermal insulation in their water tank.

In addition, the users have recommended the following suggestions for improving the water tank:

1. Use shade or plant room to avoid direct heat and use insulation.

2. Providing tank with insulation could reduce water temperature.

3. Make a new product that includes insulation materials and shade in itself. And provide a color that will not absorb heat and it should be in a good appearance.

4. Shade is must for water tank on roof.

5. Make cooling system inside water tank in summer season.

\section{Discussion}

There are many characteristics that may have an impact on the selection of water tanks. As mentioned above, most of these characteristics are important factors in the selection of water tanks. In addition, the importance of these characteristics varies according to the development and application of the use of the water tank. For example, the needs of the irrigation tank differ from 


\section{Journal of Student Research}

Fourth Middle East College Student Research Conference, Muscat, Sultanate of Oman

the domestic tank used for human consumption, since the irrigation tank should not give the characteristics affecting water quality much as it does with the domestic tank. Furthermore, Material of the tank is an important factor of selecting tanks. The material should withstand corrosion and stresses. Tank manufacturer must select an economical manufacturing method in order to reduce the cost. The cost is the main factor of selecting water tank. Thermal conductivity is also important, but it is limited in curbing heat transfer to the water inside tank. Figure 9 illustrates the importance of integrating all these characteristics for optimal selection.

Figure 10. Water tank characteristics.

After completing the data analysis, the results indicate that sweet water tanks used for human usage must be made of non-rusting or corrosion materials, that they do not affect the physical or chemical properties of the water, and that there should be no change in the color, taste or smell of water, and have no adverse effect on human health. The right selection of low capacity tank for storing sweet water is polyvinyl chloride tank. On the other hand, for large capacity tank to store sweet water the best selection is the stainless-steel tank. Moreover, the best choice among water tanks to store irrigation water is the carbon steel tank. However, it is found that the stainless-steel tank is the best choice among water tanks to store seawater. Also, it is found that the carbon steel tank is the best choice for storing sewage water.

Material thermal conductivity has less effect on material selection and the temperature rising can be solved by using a good thermal insulator. Thermal insulators have a major role in reducing the water temperature in the tank and thus solve the problem of rising water temperatures during the summer.

One of the most important challenges at the present time is providing of suitable drinking water for human consumption in most countries, especially those countries that having lack water reserves. Most people resort to the use of water tanks in different capacities for the retention of quantities of this water for daily use. Many people do not realize that prolonged water storage has affected water quality and growth of bacteria causing many diseases. Choosing the right size for the tank is important in avoiding the damage caused by storing the water for a long period. In addition, the design of the reservoir in terms of entry and exit water has a significant impact in the process of mixing water and avoid the phenomenon of short circuit.

\section{Conclusion}

Over time, several types of water tanks appeared, which differed on the nature of the place where the tank would be installed. However, they all agreed on the same needs and safety precautions. In addition, due to the high elevation in residential buildings nowadays, they rely mainly on water tanks of various kinds, in order to provide us with usable water smoothly and continuously. On the other hand, if they rely only on the lines of central water networks, it is very difficult to reach the water to the high floors without pumping and this is what made the water tanks the best solution in front of the human to get his needs of clean water without problems.

The study has achieved the main goal of the project, which is identifying the selection criteria of water tanks for different applications and environments. Moreover, it has identified the influences of tanks on environment and it has studied the cost effect on water tank selection. Also, it has studied the influences of tanks on water and human being health.

The building owners have to ensure that the tank is isolated from both sides of the interior and exterior materials resistant to water and humidity, and these things easy to be done by a specialist company. In addition, it is recommended that the tank is also thermally insulated to ensure that the water is kept the same properties and safe nature. Furthermore, providing the tank with a layer of 


\section{Journal of Student Research}

Fourth Middle East College Student Research Conference, Muscat, Sultanate of Oman

anti-ream and algae can prevent the growth of bacteria. In addition, it is recommended to follows up the general condition of the tank regularly and cleaning of the tank, because it relates to the safety of human. It is suggested that before buying an industrial tank, it is better to analyze whether the place will be installed in the right conditions, because bad infrastructure sometimes may eventually affect the cost by increasing it and make the user pay more than usual in the adjustments.

\section{Acknowledgements}

The authors want to acknowledge the mechanical engineering department at Middle East College for providing the full support which realized this research.

\section{References}

Duer M.J (2006) The science of mixing and improving water quality in water storage tanks. United States: Tideflex Technologies

Graham, J. P. and VanDerslice, J. (2007) 'The effectiveness of large household water storage tanks for protecting the quality of drinking water', 1

Kotler, P., Burton, S., Deans, K., Brown, L., \& Armstrong, G. (2013) Market segmentation, targeting and positioning. In Marketing (9th ed.). NSW: French's Forest, N.S.W., Pearson Australia [Online] available from<https://en.wikipedia.org/wiki/Target_audience\#cite_note-:0-1> [11 Nov 2018]

Olson, C.T. and DeBoer, D.E. (2007) 'the Effects of Tank Operation and Design Characteristics on Water Quality in Distribution System Storage Tanks', 17 